\title{
NUMERICAL ANALYSIS OF THE SEEPAGE CHARACTERISTICS OF SLOPES WITH WEAK INTERLAYERS UNDER DIFFERENT RAINFALL LEVELS
}

\author{
YU, S. - ZHANG, J.*-REN, X. \\ College of Water Conservancy and Hydropower Engineering, Hohai University, Nanjing \\ 210098, China \\ *Corresponding author \\ e-mail: zhangjixun@hhu.edu.cn; phone: +86-159-5050-6212 \\ (Received $13^{\text {th }}$ May 2019; accepted $16^{\text {th }}$ Jul 2019)
}

\begin{abstract}
In order to study the seepage characteristics of slopes with weak interlayers under different rainfall levels, the finite element analysis model was established using the Seep/w module in Geostudio2018. The calculation conditions of big rain, heavy rain and rainstorm were carried out. The variation of pore pressure at different monitoring points and monitoring lines was obtained. The results show that under different rainfall levels, the pore pressure of slope surface increases first and then decreases, reaches saturation in the process of rainfall, and decreases gradually after the rainfall, and the pore pressure presents shapes like a backwards $\mathrm{S}$ at the elevation of weak interlayers. The wetting front infiltrates the silty clay layer uniformly and a "sudden change" occurs at the elevation of weak interlayers. The rainfall infiltration degree under low intensity and long duration is greater than that of high intensity and low duration. The research results will provide a reference for the understanding of the rainfall infiltration mechanism of the slope with weak interlayers as well as the slope treatment and prevent the catastrophic disasters occurring in slopes.
\end{abstract}

Keywords: numerical studies, unsaturated soils, interlayers, pore water pressure, wetting front, geostudio

\section{Introduction}

Weak interlayers widely exist in the interior of the slope (Long-Qi and Neng-Pan, 2016; Yang et al., 2018), not only controlling its stability (Kulasingam et al., 2004), but also having a great influence on the seepage characteristics (Thompson, 1984; Ming et al., 2011). Meanwhile, Rainfall is the key factor affecting slope safety (Rahardjo et al., 2005). Rainfall causes the rise of the underground water level (Chaplot et al., 2003) and the reduction of shear strength in rock and soil (Fang et al., 2015), thus leading to catastrophic disasters. According to some relevant studies (Lee et al., 2013), rainfallinduced landslides account for $51 \%$ of the total number of landslides. Therefore, it is of great significance to study the effects of rainfall on slopes with weak interlayers.

Rainfall-induced landslides are mainly characterized by shallow instability in the early stage and overall slipperiness in the later period (Zhang and Wang, 2012). The influence of rainfall on slope seepage is mainly reflected in the formation of transient saturation zone at the foot of the slope, and then diffuses to its depth (Philip, 1993). Previous studies have focused on the influence of different rainfall types and different soil or rock mechanical properties on the seepage characteristics and slope safety. For example, soil properties such as the anisotropy ratio (Zhang and Lin, 2016), the saturated hydraulic conductivity (Woolhiser et al., 1996), the matric suction (Lim et al., 1996), the cohesive strength (Schultz et al., 1985) and the internal friction angle (Mitchell et al., 1972) all play important roles, and rainfall types such as different peak 
rainfalls (Sheng, 2000), different rainfall levels (Tian, 2014) and different return periods (Ng et al., 2001) equally have a great impact. Meanwhile, antecedent rainfall should be considered before starting numerical calculations (Rahimi et al., 2011).

As a weak part in the slope, interlayers have the characteristics of high permeability and low shear resistance, and they are sensitive to rainfall. Experimental study on slopes with a thin soft band layer under rainfall has been conducted by Elkamhawy et al. (2018) to study the seepage characteristics and failure modes, but discussions are not sufficient, theoretical methods were proposed such as the shear strength reduction method (Jie-Qun et al., 2013) and the three-dimensional combined rotationaltranslational mechanism (Huang et al., 2017) but they are applied under the condition without rainfall. In addition, the seepage stability mechanism of weak interlayer under rainfall condition is still lacking, which needs to be further studied.

Previous studies have mostly focused on the impact of rainfall types on the seepage characteristics of homogeneous slopes or its stability with interlayers. However, few studies have involved systematic analysis of seepage characteristics, which can reveal the mechanism of rainfall infiltration and rock and soil deterioration. So in this paper, numerical model of a slope with weak interlayers was established with Geo-studio and seepage characteristics were quantitatively studied under different rainfall levels. The results of the research will provide a reference for the understanding of rainfall infiltration mechanism of the slopes with weak interlayers as well as the its treatment and prevent the catastrophic disasters occurring in slopes.

\section{Methods and theory}

\section{Model and boundary conditions}

The simulation model was established according to the geometry presented by Yang et al. (2008), as shown in Figure 1. However, Yang et al. (2008) did not give a systematic description of the seepage characteristics. In this paper, the monitoring points and monitoring lines are adopted to illustrate the seepage characteristics not only on the slope surface but also along its elevation, which can give a better understanding. The slope height of the first and second grade is $10 \mathrm{~m}$, and the third one is $8 \mathrm{~m}$ high. The slope ratios of all the three stages are 1:1. There are two weak interlayers, which are the ribbon structure layer with a thickness of $2 \mathrm{~m}\left(8.2^{\circ}\right.$ with horizontal direction). For the correct reflection of rainfall infiltration, the depth of the foundation is set to $22 \mathrm{~m}$. The mesh size is refined to $0.2 \mathrm{~m}$ in weak interlayers and $0.4 \mathrm{~m}$ in other parts. The whole model is divided into 5,481 nodes and 5,375 elements.

In order to study the seepage characteristics of the slope surface at different locations, four monitoring points on the surface of the slope are taken. They are monitoring point 1 located at $(30,50)$, monitoring point 2 located at $(41.5,42)$, monitoring point 3 located at $(56.5,34)$ and monitoring point 4 located at $(66,22)$. Four monitoring lines are also taken to investigate the seepage law in the slope at different locations; they are monitoring line 1 located at $\mathrm{x}=30$, monitoring line 2 located at $\mathrm{x}=41.5$, monitoring line 3 located at $\mathrm{x}=56.5$ and monitoring line 4 located at $\mathrm{x}=66$.

To study the rainfall infiltration, the initial condition should be defined. In this paper, the initial seepage field is calculated by the initial infiltration line shown in Figure 1. $\mathrm{CDEF}$ is the rainfall infiltration boundary, $\mathrm{BC}, \mathrm{FG}$ and $\mathrm{AH}$ are the impervious boundary, $\mathrm{AB}$ is the fixed head boundary of $26 \mathrm{~m}$ and $\mathrm{HG}$ is the $15 \mathrm{~m}$ fixed head boundary. 


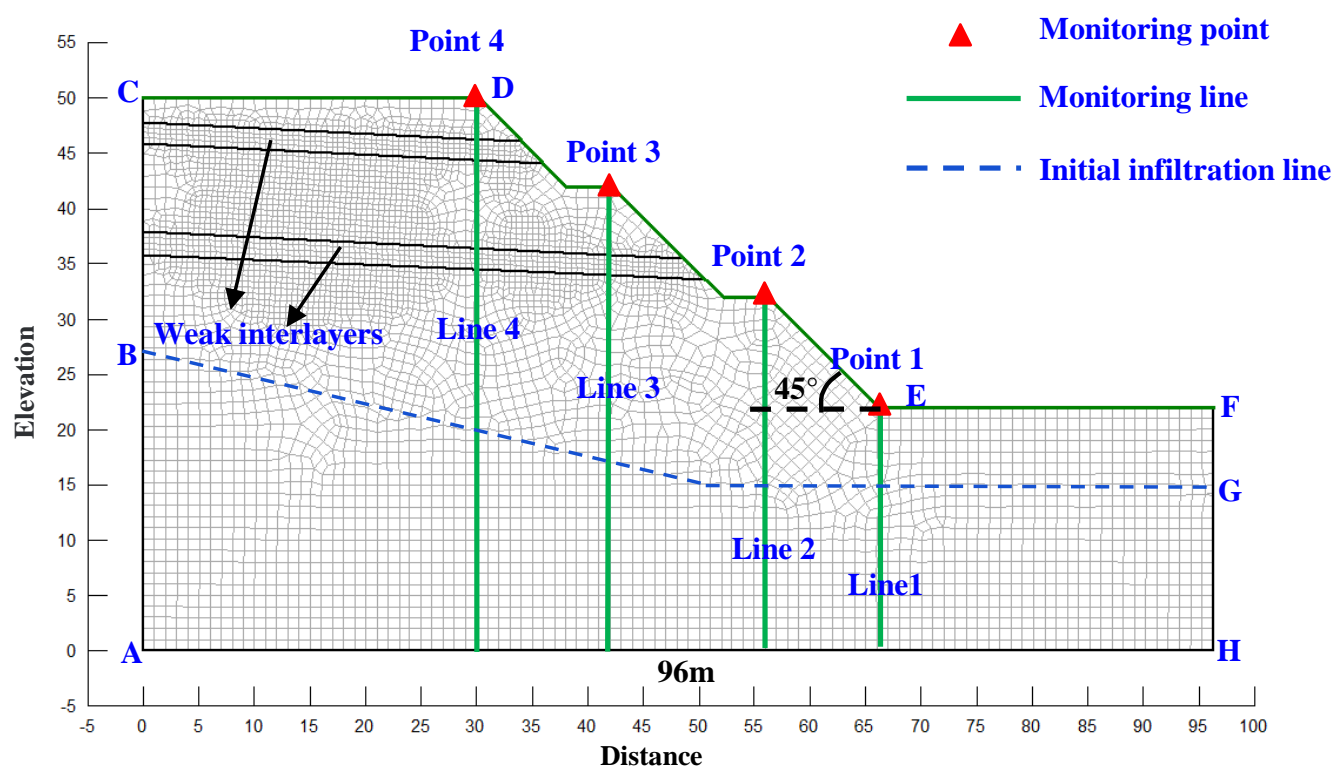

Figure 1. Slope simulation model

According to the climate monitoring data of Linchang Highway, three simulation schemes are determined for different rainfall levels: big rain, heavy rain and rainstorm on the basis of the standard of State Meteorological Administration of China. The rainfall intensity is $1.67 \mathrm{~mm} / \mathrm{h}$ in big rain condition, and the duration is $4 \mathrm{~d}$. The rainfall intensity is $3.33 \mathrm{~mm} / \mathrm{h}$ in heavy rain condition, and the duration is $2 \mathrm{~d}$, while the rainfall intensity is $6.67 \mathrm{~mm} / \mathrm{h}$ in rainstorm condition, and the duration is $1 \mathrm{~d}$. The calculation time is set to $5 \mathrm{~d}$ in Geo-studio and the specific rainfall conditions are shown in Table 1 .

Table 1. Rainfall conditions

\begin{tabular}{c|c|c|c}
\hline Rainfall level & Rainfall intensity $(\mathbf{m m} / \mathbf{h})$ & Rainfall duration time (d) & Rainfall amount $(\mathbf{m})$ \\
\hline Big rain & 1.67 & 4 & 0.16 \\
Heavy rain & 3.33 & 2 & 0.16 \\
Rain storm & 6.67 & 1 & 0.16 \\
\hline
\end{tabular}

\section{Material properties}

The SEEP/W module in Geo-studio is utilized to simulate the rainfall infiltration, and the unsaturated seepage equation can be expressed as (Fredlund and Rahardjo, 1993):

$$
\frac{\partial}{\partial x_{i}}\left[k_{i j}^{s} k_{r}\left(h_{c}\right) \frac{\partial h_{c}}{\partial x_{j}}+k_{i 3} k_{r}\left(h_{c}\right)\right]+Q=\left[C\left(h_{c}\right)+\frac{\theta}{n} S_{s}\right] \frac{\partial h_{c}}{\partial t}
$$

where $x_{\mathrm{i}}, x_{\mathrm{j}}$ is the position coordinates in $\mathrm{i}$ and $\mathrm{j}$ direction, $k_{\mathrm{ij}}^{\mathrm{s}}$ is the saturated permeability tensor, $k_{\mathrm{r}}$ is the relative water permeability, $h_{\mathrm{c}}$ is the pressure head, $\beta$ is the unsaturated coefficient, $S_{\mathrm{s}}$ is the pondage restored in soil, $Q$ is the input and output of the flux, $C\left(h_{\mathrm{c}}\right)$ is the water capacity which is the function of $h_{\mathrm{c}}, n$ is the porosity and $t$ is the time. 
The water characteristic curves (SWCC) characterizing the variation of volumetric moisture content or permeability coefficient with matric suction, which was proposed by Fredlund and Rahardjo (1993) in 1994, can obtain the closed solution of volume water content under the range of negative pore pressure from 0 to $-1 \times 10^{6} \mathrm{KPa}$ and is adopted in this paper:

$$
\theta_{w}=C_{\phi} \frac{\theta_{s}}{\left\{\ln \left[e+\left(\frac{\phi}{a}\right)^{n}\right]\right\}^{m}}
$$

where $\theta_{\mathrm{w}}$ is the volumetric moisture content, $C_{\phi}$ is the modified function, $\theta_{\mathrm{s}}$ is the saturated volumetric moisture content, $\phi$ is the negative pore water pressure.

According to the volume water content function of Fredlund (Fredlund and Rahardjo, 1993), SEEP/W module in Geo-studio software sets the corresponding governing equation (Fredlund and Rahardjo, 1993), which can be expressed as:

$$
k_{w}=k_{s} \frac{\frac{\sum_{i=j}^{N} \theta\left(e^{y}\right)-\theta(\psi)}{\sum_{i=1}^{y}} \theta\left(e_{i}^{y}\right)}{\sum_{i}^{N} \frac{\theta\left(e^{y}\right)-\theta_{s}}{e_{i}^{y}} \theta^{0}\left(e_{i}^{y}\right)}
$$

where $k_{\mathrm{w}}$ is the permeability coefficient calculated by water content or negative pore water pressure, $k_{\mathrm{s}}$ is the saturated permeability coefficient of slope soil, $y$ represents the dummy variable of the negative pore water pressure algorithm, $i$ is the numerical distance between $j$ and $N, j$ is the minimum negative pore water pressure described by the final function, $N$ is the maximum negative pore water pressure described by the final function and $\Psi$ corresponds to the first $j$ of negative pore water pressure. $\theta_{0}$ is the initial value of the equation.

The slope soil is composed of silty clay. The physical and mechanical properties of silty clay and interlayers are determined according to the experiment and field investigation. The values of parameters are shown in Table 2, and the SWCC curves are shown in Figure 2.

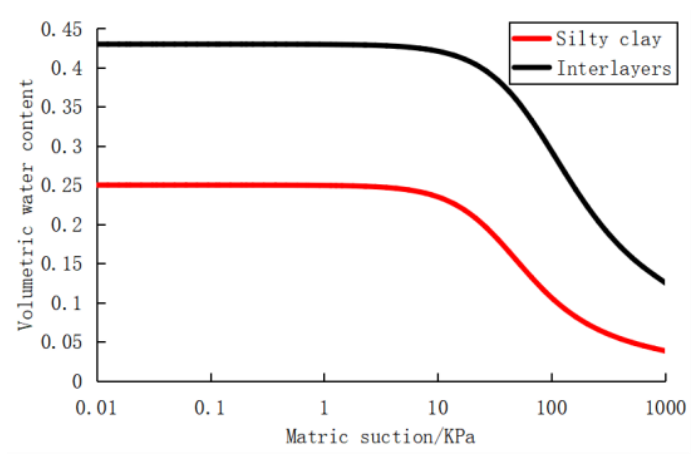

(a) Volume water content function

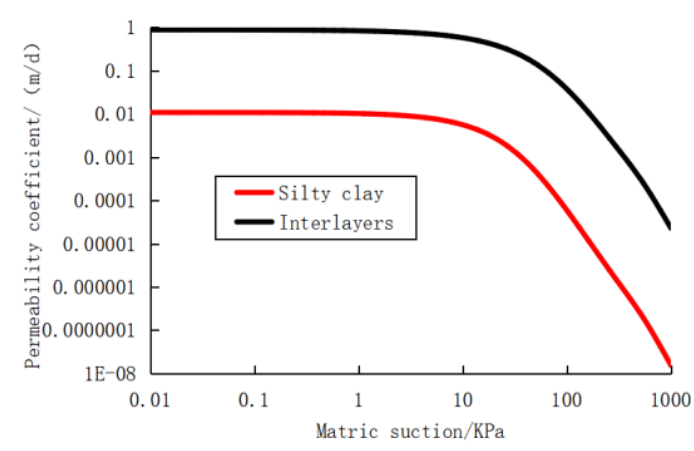

(b) Permeability coefficient function

Figure 2. Soil-water characteristic curve 
Table 2. Physical and mechanical properties of materials

\begin{tabular}{|c|c|c|c|c|c|}
\hline Materials & $\begin{array}{l}\text { Weight } \\
\left(\mathbf{k N} / \mathbf{m}^{3}\right)\end{array}$ & $\begin{array}{c}\text { Cohesive } \\
\text { strength }(\mathrm{KPa})\end{array}$ & Internal friction angle & $\begin{array}{l}\text { Permeability } \\
\text { coefficient } \\
(\mathbf{m} / \mathbf{d})\end{array}$ & $\begin{array}{c}\text { Saturated } \\
\text { water content }\end{array}$ \\
\hline Silty clay & 25 & 31 & 27 & 0.0108 & 0.25 \\
\hline Interlayers & 12 & 16 & 13 & 0.88128 & 0.43 \\
\hline
\end{tabular}

\section{Results}

\section{Comparison of pore water pressure variation on the slope surface}

The variation of pore pressure at different monitoring points (monitoring point 1 , monitoring point 2, monitoring point 3 and monitoring point 4) is shown in Figure 3. Under the action of rainfall, the slope surfaces at different positions experienced the process from unsaturated to saturated and then to unsaturated, that is, the pore pressure increases to 0 at first and then decreases, except for monitoring point 3 , and the variation of pore pressure caused by different rainfall grades is quite different. For monitoring point 1 , monitoring point 2 and monitoring point 4 , pore pressure goes through a process of rapidly rising to saturation, continuing and then decreasing under different rainfall levels, and the time when the slope surface reaches saturation is positively proportional to the rainfall level. However, it is worth noting that the big rain, which represents the long period of weak rainfall, has the ability to make the duration of slope surface saturation longer (average 0.5 day for rainstorm, 1 day for heavy rain and 2.4 days for big rain). Although the time of the big rain condition when slope surface reaches saturation is later than other rainfall levels (heavy rain and rainstorm). It means that the effect of a short period of heavy rain on the slope seepage characteristics is less than that of a long period of weak rain. This is because prolonged weak rainfall can make slope infiltration more sufficient, and large amounts of rainwater are prevented from draining away from the slope surface, which is closely related to the infiltration rate of the soil (Jun-Ping et al., 2016), if the rain intensity is larger than the infiltration rate of soil, then rainfall infiltration will be determined by infiltration rate rather than rainfall intensity. Therefore, more attention should be paid to slope safety monitoring and drainage in the case of long-term weak rainfall.

For monitoring point 3, the change of pore pressure is different from other monitoring points, although pore pressure increases during rainfall, the slope surface does not reach the saturated state. This is because monitoring point 3 is located at the top of the secondary slope. Under this condition, rainwater not only infiltrates from monitoring point 3 , but also drains to the lower part of the slope. This phenomenon is observed in Elkamhawy's works (Elkamhawy et al., 2018) and is discussed in section 4. Therefore, the increase of pore pressure at monitoring point 3 is significantly smaller than that at other monitoring points.

\section{Comparison of pore water pressure variation in the slope}

\section{Variation of pore water pressure of different time under a rainstorm}

Variation of pore water pressure of different time under rainstorm is shown in Figure 4. Pictures on the left side are the pore pressure distribution of the whole monitoring line, while on the right side are the region where local pore pressure changes 
dramatically. The pore pressure distribution on different monitoring lines is also very different, the monitoring line 1 and 2 did not pass through the weak interlayer, while the monitoring line 3 passed through the second weak in

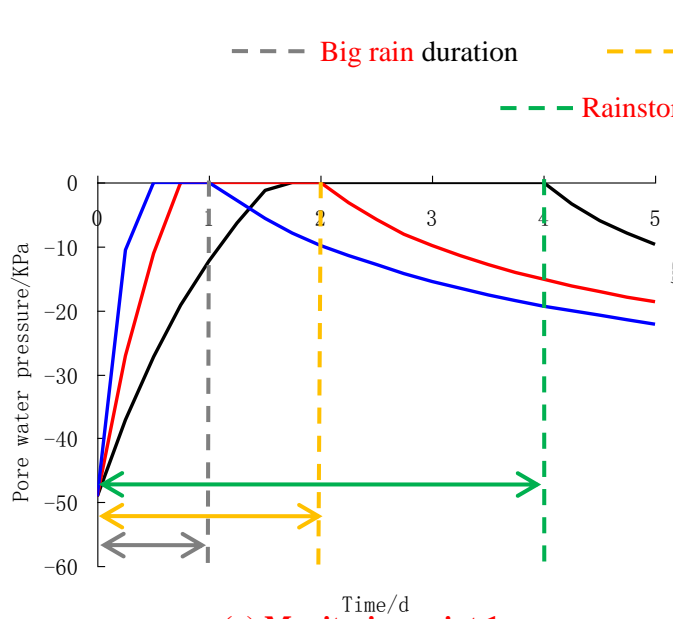

(a) Monitoring point 1

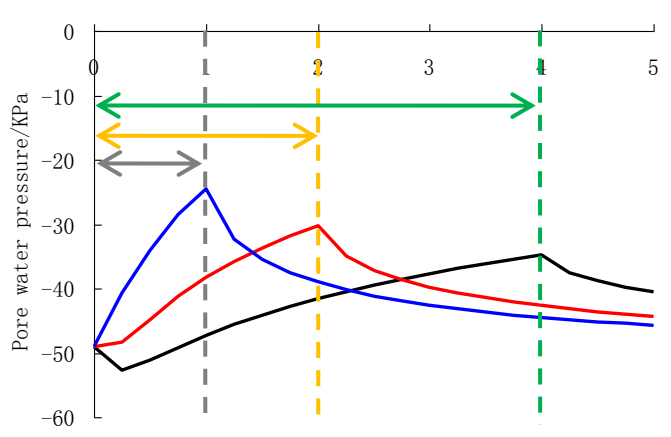

(c) Monitoring/d point 3
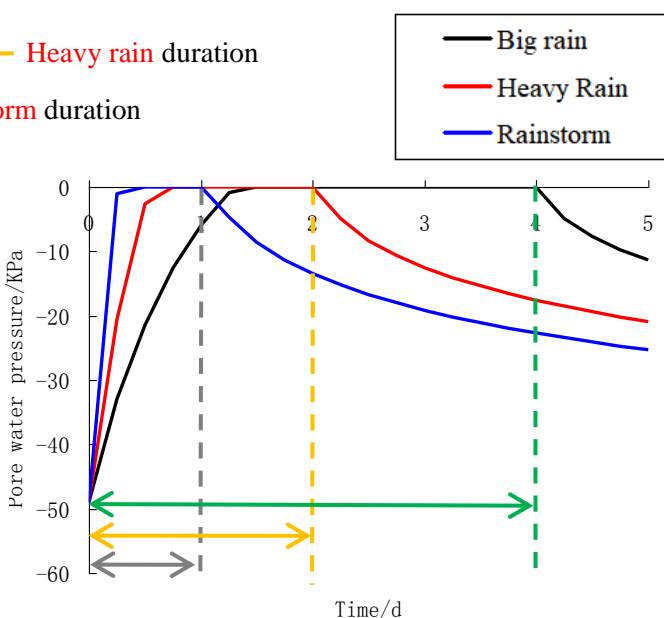

(b) Monitoring point 2

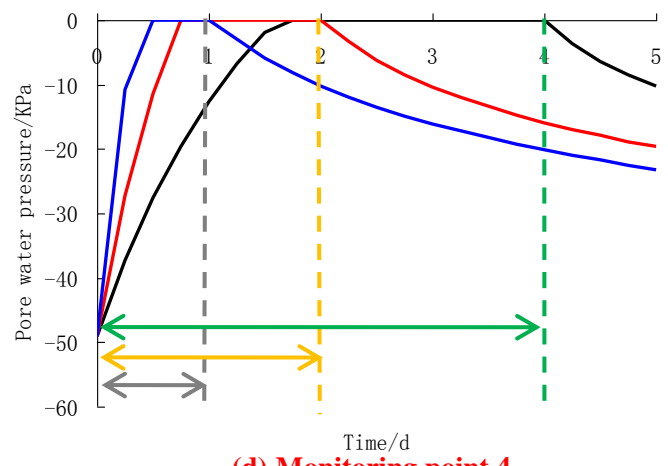

(d) Monitoring point 4

Figure 3. Pore water pressure of different monitoring points

terlayer and the monitoring line 4 simultaneously passed through two weak interlayers.

For monitoring line 1, it is not only affected by rainfall infiltration in the process of rainfall, but also by the drainage of upper rainwater because it is located in the lower part of the slope. Therefore, except for the shallow part (elevation 18-22 m), which is greatly affected by rainfall on the surface of the slope, the pore pressure increases linearly with the elevation and remains unchanged during rainfall. Compared with the local enlarged image on the right, the pore pressure on the shallow part rapidly increases to saturation during rainfall, and then gradually develops to the depth. After the rain stops, the pore pressure of the slope surface gradually drops, but the affected area is only limited to the elevation of 18-22 $\mathrm{m}$ and has a small impact on the rest.

For monitoring line 2, except the area where the pore pressure in the surface of the slope changes sharply (elevation 28-32 m), the rest of the area first remains unchanged with the elevation (elevation 22-28 m), and then presents a linear increase distribution with the elevation. For the shallow part (figures on the right), the change of pore pressure is similar to that of monitoring line 1 . 


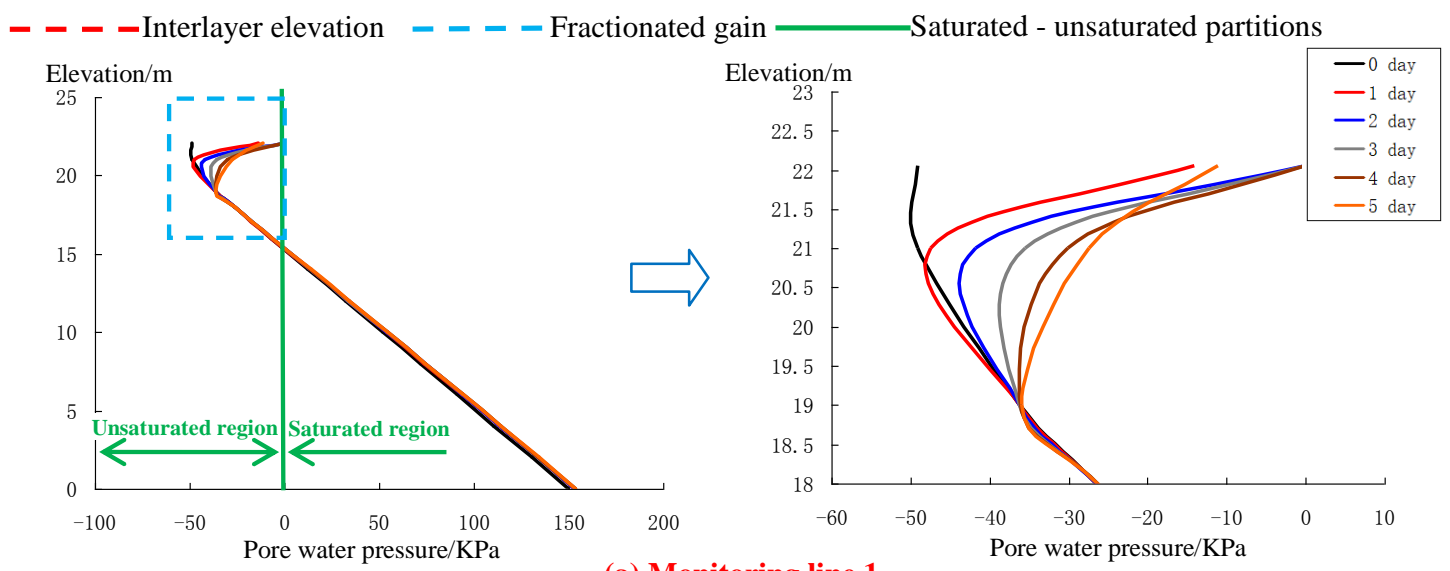

(a) Monitoring line 1
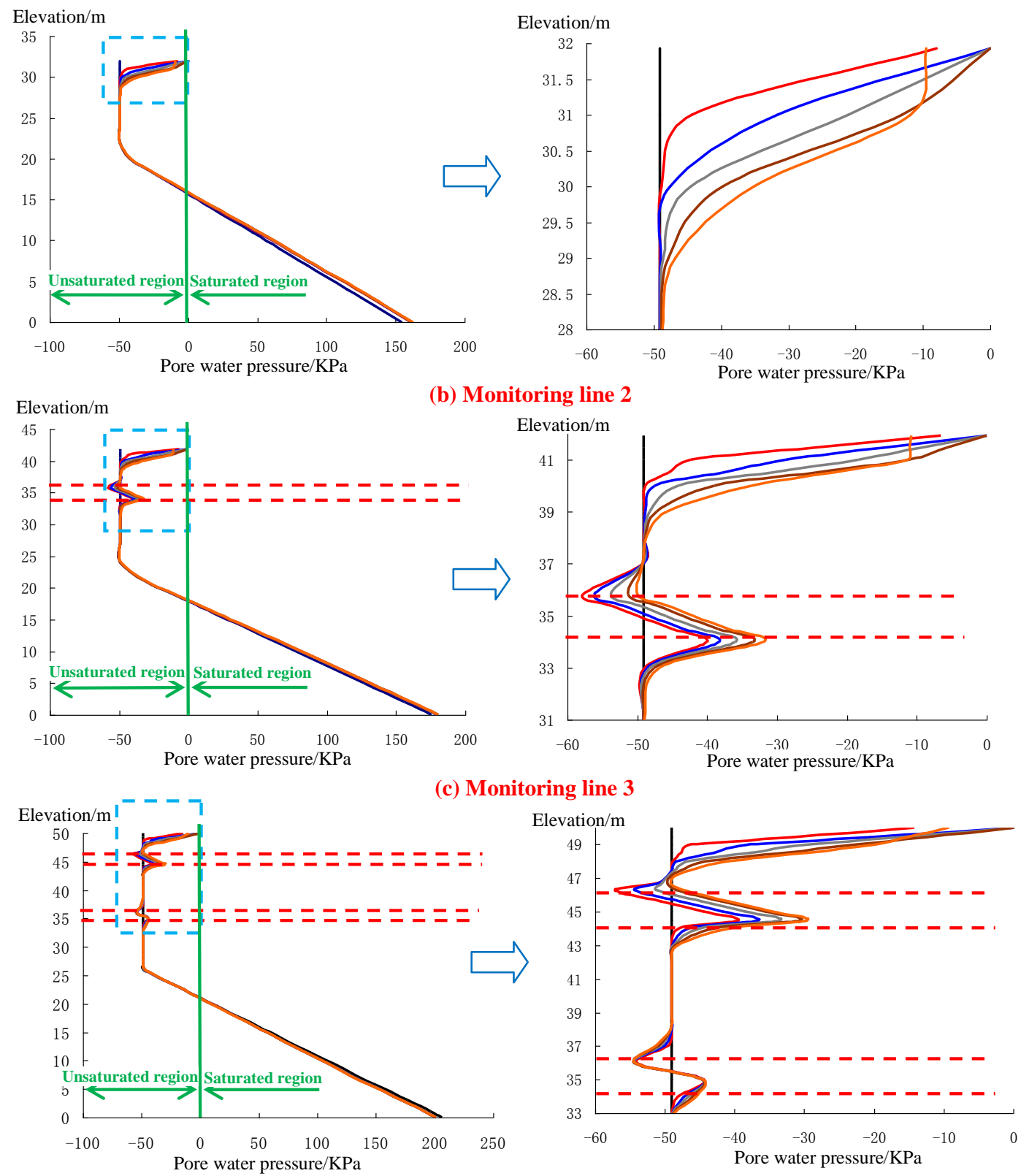

(d) Monitoring line 4

Figure 4. Variation of pore water pressure of different time under a rainstorm 
For monitoring line 3, in addition to the dramatical changes of surface pore pressure, there is also an obvious variation at the elevation of the weak interlayer. The pore pressure at the weak interlayer presents obvious shapes like a backwards $S$ along the elevation, that is, the upper and lower surface pressure of the weak interlayer decreases sharply, while the internal pore pressure of the weak interlayer is large, forming a more obvious drainage effect. This is because the permeability coefficient of the weak interlayer is smaller than that of the silty clay, so this kind of shape is formed, and the variation range of pore pressure in the weak interlayer is also large.

For monitoring line 4, it passes through two weak interlayers, so the pore pressure of the monitoring surface presents two shapes like a backwards $S$. The first one is consistent with the change rule of monitoring point 3, while the second one is slightly different, mainly reflected in that the overall change range of pore pressure is smaller than that of the upper weak interlayer. Meanwhile, the change range of pore pressure in the weak interlayer at different times is also not so obvious, which is mainly due to the deep distance from the second weak interlayer to the slope surface and the impact of rainwater infiltration is small.

\section{Variation of pore water pressure on the 5th day under different rainfall levels}

Variation of pore water pressure on the $5^{\text {th }}$ day under different rainfall levels is shown in Figure 5. Pictures on the left side are the pore pressure distribution of the whole monitoring line, while on the right side are the region where local pore pressure changes dramatically. As can be seen from the left side, the change of pore pressure with elevation is consistent with that in Figure 4, and the shapes like a backwards $\mathrm{S}$ also exist in monitoring 3 and 4 . However, when the rain stopped, the surface pore pressure would fall back in different order under different levels of rainfall, as shown on the right side of Figure 5. Rainstorm falls the fastest in the shallow part of the slope, followed by big rain, followed by a heavy rain. Meanwhile, the pore pressure at the weak interlayer is also different, and the pore pressure of the rainstorm is close to that of the heavy rain, the pore pressure of big rain is relatively backward. This is also easy to understand, because the low rainfall intensity makes the less water needed to be excreted from the weak interlayer, and the pore pressure of heavy rain whose rainfall intensity in the lowest is correspondingly smaller than other rainfall levels.

\section{Variation of the wetting front}

\section{Definition of the wetting front}

Rainfall infiltration is a typical unsaturated problem, according to Bodman et al. (1944), for the general rainfall process, the water content of the slope can be divided into four parts: saturation zone, transition zone, conduction area and wetting area. The lowest end of the wetting area is the wetting front, as shown in Figure $6 a$.

The soil moisture content is constantly changing with the continuous rainfall process. Fredlund (Fredlund and Rahardjo, 1993) proposed that when rainfall is applied to the slope surface, the soil surface moisture content increases rapidly from initial water content $\theta_{0}$ to saturated water content $\theta_{s}$. And as the rainfall continues, the wet front is continuously advanced to the deep side of the slope, and the water content curve gradually becomes smooth. The variation of soil moisture content over time is shown in Figure $6 b$. 

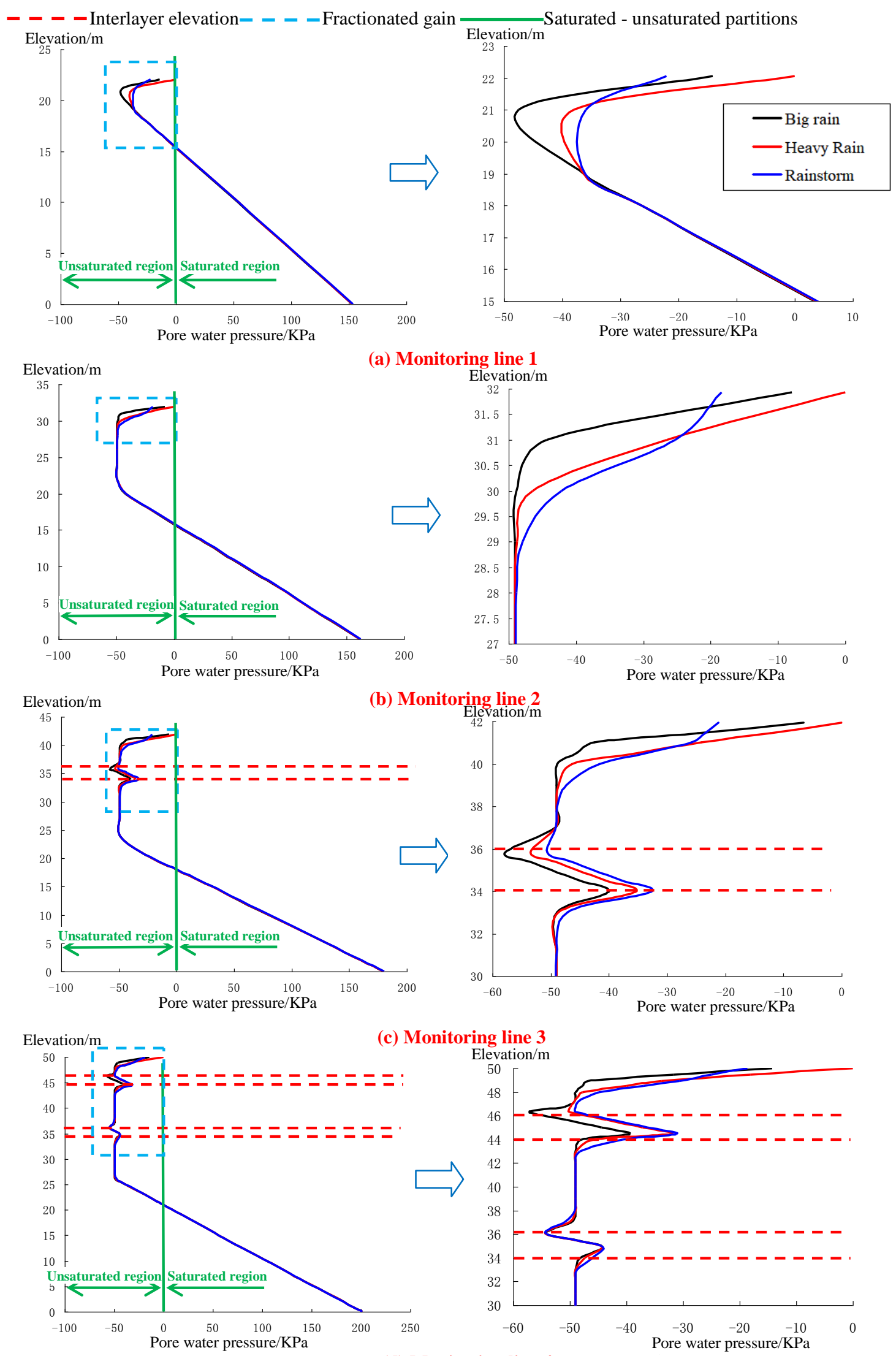

(d) Monitoring line 4

Figure 5. Variation of pore water pressure in the 5th day under different rainfall levels 


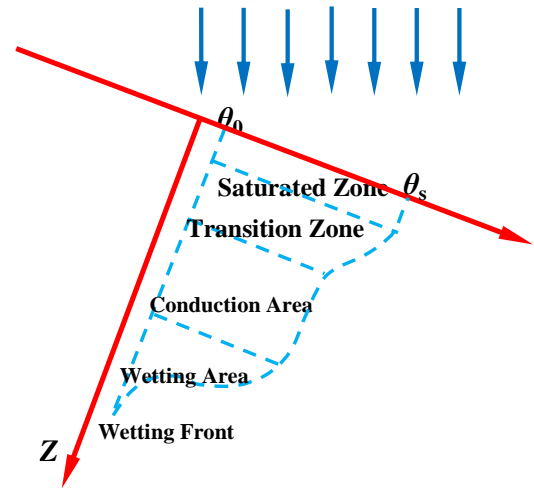

(a)

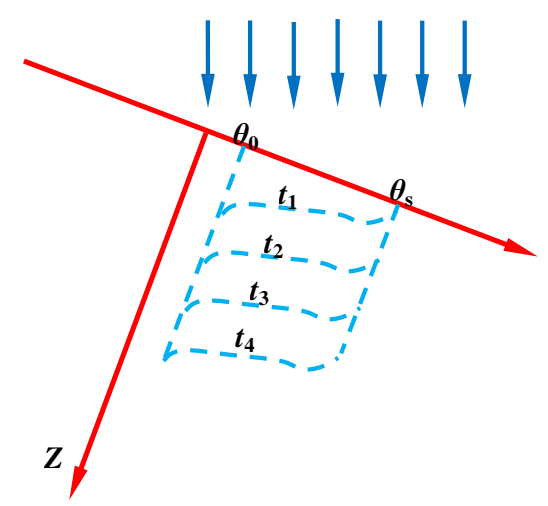

(b)

Figure 6. Wetting front diagram. $\boldsymbol{a}$ and $\boldsymbol{b}$ : Typical water cut profile of water infiltration

\section{Variation of the wetting front of slope under different rainfall grades}

The wetting front changes under different levels of rainfall are shown in Figure 7. As can be seen from the graph, the law of the development of wet front under different rainfall grades is almost the same, that is, there is uniform infiltration on the surface of clay slope. However, a sudden change in the weak interlayer occurs because the permeability coefficient in the weak interlayer is larger than that in the silty clay, so that rainfall is easier to infiltrate than other parts of the slope. Under the different rainfall levels, the development of the wetting front of rainstorm is less than that of a heavy rain, and less than that of a big rain, which indicates that rainfall infiltration under the condition of long duration and low rainfall intensity is more abundant than the high rainfall intensity of short duration. This is because, under the same rainfall condition, the high-intensity rainfall cannot completely infiltrate into the slope body, most rainwater is lost on the its surface, while the low-intensity rainfall is just the opposite, and the rainfall can fully infiltrate into the soil mass. Therefore, for the actual slope engineering, it is more likely to lose stability in the case of long duration and low rainfall intensity. At the same time, because of the high permeability of the weak interlayer, the internal pore pressure increases and the soil parameters deteriorate under the condition of rainfall, which makes it easier to form the potential failure surface. Therefore, the reinforcement of weak interlayer is also very important.

\section{Validation and discussion}

Elkamhawy et al. (2018) carried out the experimental study on failure mechanism of a slope with weak interlayers triggered by intensive rainfall. Experimental results showed that during the time of rainfall, the infiltrated water flowed out from the slope through the weak interlayer near to the toe causing piping and local failure, then the tensile cracks formed at the top grew and expanded due to sliding of the failed soil blocks along the weak interlayer, which is in accordance with our numerical results. In section 3.1 and 3.2 the pore water pressure in monitoring point 1 and monitoring line 1 have higher values than other parts, which means that rain water is abundant at the foot of the slope. So in order to restrict the growth of positive pore water pressure at the toe, we can apply the method of constructing horizontal and vertical drains to discharge the infiltrated water directly. 


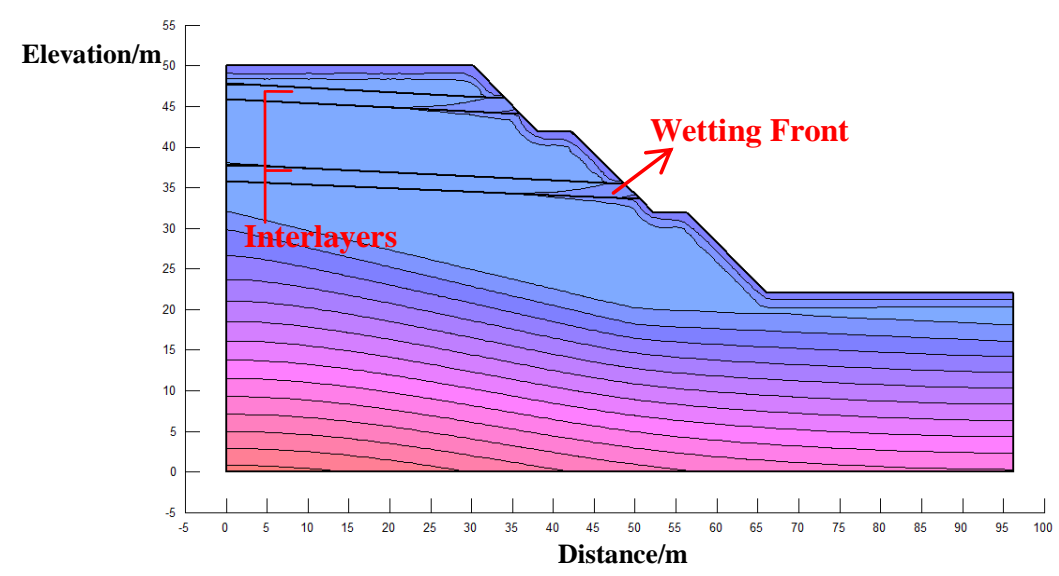

(a) Heavy rain condition $\left(5^{\text {th }} \mathrm{d}\right)$

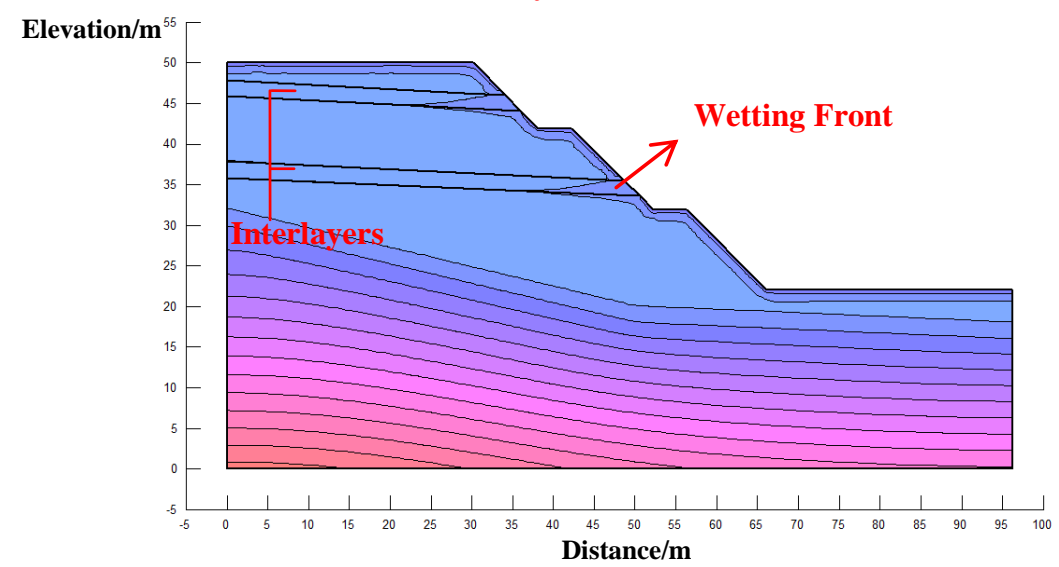

(b) Rainstorm condition $\left(5^{\text {th }} \mathrm{d}\right)$

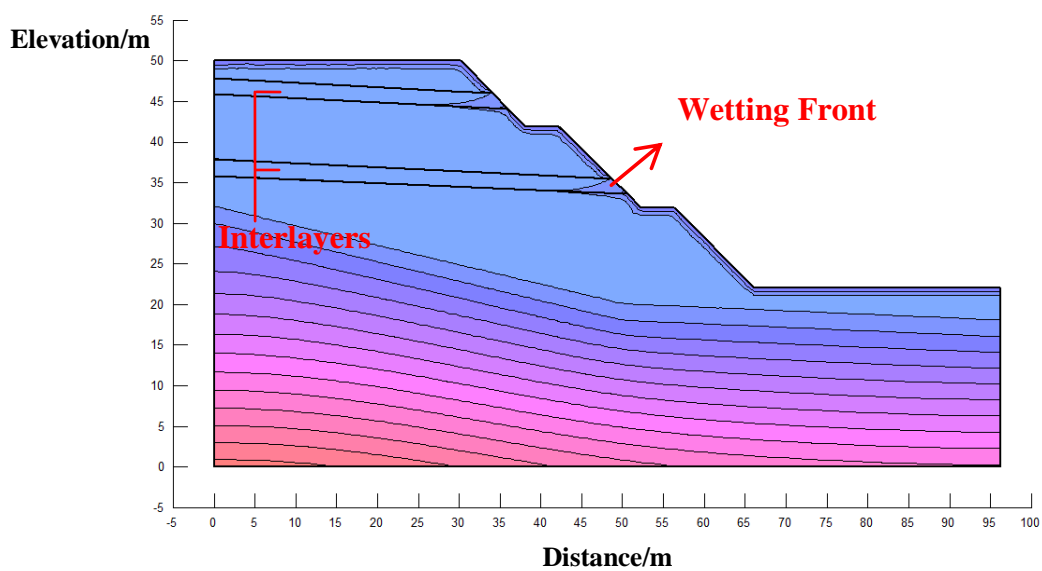

(c) Torrential rain condition $\left(5^{\text {th }} \mathrm{d}\right)$

Figure 7. Variation of the wet front under different rainfall grades

In addition, the shapes like a backwards $S$ of pore water pressure at the elevation of weak interlayers mean that weak interlayers is a potential leakage passage for rainfall infiltration, and along which the soil block tend to slide, so it is necessary to make proper reinforcement treatments of weak interlayers. For example, we can use soil nailing to link between the wedges prone to slide with the stable soil under the weak interlayers. 
Moreover, in our simulation, we found that the surface pore water pressure undergoes a longer period of saturation in big rain than heavy rain and rainstorm, which means that the the rainfall with low intensity and long duration has a worse effect on slope than the rainfall with high intensity and short duration, so it is very important to pay more attention to the rainfall with low intensity and long duration and prevent the landslides.

\section{Conclusions}

In this paper, the seepage characteristics of the slope with weak interlayers under different rainfall levels are numerically simulated, and the following conclusions can be obtained:

(1) Under different rainfall grades, the surface pressure of the slope at different elevations increases rapidly and reaches saturation at the time of rainfall, and decreases rapidly after the rainfall. Under the same rainfall amount, high rainfall grade makes the time when pore pressure reaches saturation earlier, and the long duration of the rainfall makes the longer duration time when the pore pressure reaches saturation.

(2) Rainfall has a great influence on the pore pressure variation in the surface layer and weak interlayer of the slope, but has limited effect on the other parts. The pore pressure distribution in different positions of the slope is also quite different. The pore pressure of the lower part increased linearly with the elevation, and the pore pressure of the middle and lower parts remains unchanged first and then increases linearly with the elevation. The pore pressure of the upper and middle parts shows shapes like a backwards $\mathrm{S}$ along with the elevation at the weak interlayer.

(3) Wetting front uniformly infiltrates in silty clay layer, and "sudden change" appears in weak interlayers. Meanwhile, the development of the wetting front of low intensity and long duration rainfall is larger than that of high-intensity short rainfall.

(4) For the actual slope engineering, it is very important to pay more attention to the rainfall with low intensity and long duration and prevent the landslides.

(5) Although systematic analysis of seepage characteristics are discussed in this paper, what occurs in nature is complex, and different conditions such as the variable thickness and angles of weak interlayers, different rainfall types, duration and different slope geometry should be included in future studies.

Acknowledgements. This research was financially supported by The National Natural Science Fund (Grant No. U1765204).

\section{REFERENCES}

[1] Bodman, G. B., Colman, E. A. (1944): Moisture and energy conditions during downward entry of water into soils. - Soil Science Society of America Journal 8(8).

[2] Chaplot, V. A. M., Bissonnais, Y. L. (2003): Runoff features for interrill erosion at different rainfall intensities, slope lengths, and gradients in an agricultural loessial hillslope. - Soil Science Society of America Journal 67(3): 844-851.

[3] Elkamhawy, E., Wang, H., Zhou, B. (2018): Failure mechanism of a slope with a thin soft band triggered by intensive rainfall. - Environmental Earth Sciences 77(9): 340. 
[4] Fang, H., Sun, L., Tang, Z. (2015): Effects of rainfall and slope on runoff, soil erosion and rill development: an experimental study using two loess soils. - Hydrological Processes 29(11): 2649-2658.

[5] Fredlund, D. G., Rahardjo, H. (1993): Soil Mechanics for Unsaturated Soils. - Wiley, New York.

[6] Huang, M., Fan, X., Wang, H. (2017): Three-dimensional upper bound stability analysis of slopes with weak interlayer based on rotational-translational mechanisms. Engineering Geology. DOI: 10.1016/j.enggeo.2017.04.017.

[7] Jie-Qun, L., Lu-Wang, C., Jin-Long, L. (2013): Failure modes and stability of rock mass slope containing multi-weak interlayer. - Journal of Applied Sciences 13(21): 139-141.

[8] Jun-Ping, Y., Yan-Ling, L., Peng, D., Chun-Lei, H. (2016): Influence of anisotropy induced by fissures on rainfall infiltration of slopes. - Chinese Journal of Geotechnical Engineering. DOI: 10.11779/CJGE201601007.

[9] Kulasingam, R., Malvick, E. J., Boulanger, R. W. (2004): Strength loss and localization at silt interlayers in slopes of liquefied sand. - Journal of Geotechnical \& Geoenvironmental Engineering 130(11): 1192-1202.

[10] Long-Qi, L. I., Neng-Pan, J. U. (2016): Effect of the inclined weak interlayers on the rainfall response of a bedded rock slope. - Journal of Mountain Science 13(9): 16631674.

[11] Lee, D. H., Lai, M. H., Wu, J. H. (2013): Slope management criteria for Alishan Highway based on database of heavy rainfall-induced slope failures. - Engineering Geology 162(14): 97-107.

[12] Lim, T. T., Rahardjo, H., Chang, M. F., Fredlund, D. G. (1996): Effect of rainfall on matric suctions in a residual soil slope. - Canadian Geotechnical Journal 33(4): 618-628.

[13] Ming, L. I., Zhang, G., Zhang, J. M. (2011): Research on failure mode of clay slope containing horizontal sand interlayer under excavation conditions. - Rock \& Soil Mechanics 12(8): 197-199.

[14] Mitchell, J. K., Scott, R. F., Houston, W. N., Costes, N. C., Carrier, W. D., Bromwell, L. G. (1972): Mechanical properties of lunar soil: density, cohesion, and angle of internal friction. - Lunar \& Planetary Science Conference, January 10-13, 1972, Houston, Texas.

[15] Ng, C. W., Wang, B., Tung, Y. K. (2001): Three-dimensional numerical investigations of groundwater responses in an unsaturated slope subjected to various rainfall patterns. Canadian Geotechnical Journal 38(5): 1049-1062.

[16] Philip, J. R. (1993): Constant-Rainfall Infiltration on Hillslopes and Slope Crests. - In: Russo, D., Dagan, G. (eds.) Water Flow and Solute Transport in Soils. Springer, Berlin.

[17] Rahardjo, H., Lee, T. T., Leong, E. C. (2005): Response of a residual soil slope to rainfall. - Canadian Geotechnical Journal 42(2): 340-351.

[18] Rahimi, A., Rahardjo, H., Leong, E. C. (2011): Effect of antecedent rainfall patterns on rainfall-induced slope failure. - Journal of Geotechnical and Geoenvironmental Engineering 137(5): 483-491.

[19] Schultz, J. P., Jarrett, A. R., Hoover, J. R. (1985): Detachment and splash of a cohesive soil by rainfall. - Transactions of the ASAE 28(6): 1878-1884.

[20] Sheng, Y. (2000): Joint probability distribution of annual maximum storm peaks and amounts as represented by daily rainfalls. - International Association of Scientific Hydrology Bulletin 45(2): 12.

[21] Thompson, J. N. (1984): Insect diversity and the trophic structure of communities. Ecological Entomology 9(2): 165-178.

[22] Tian, D. F. (2014): A slope stability analysis method based on unsaturated seepage of slope and its comparison with geo-seep software. - Applied Mechanics \& Materials 540: $177-180$.

[23] Woolhiser, D. A., Smith, R. E., Giraldez, J. V. (1996): Effects of spatial variability of saturated hydraulic conductivity on hortonian overland flow. - Water Resources Research 32(3): 671-678. 
[24] Yang, Y., He, Z., Wang, B., Ma, Y. (2008): Numerical analysis of seepage characteristics of soil slope with weak interlayer under different rainfall conditions. - Mining and Metallurgical Engineering 38(03): 15-19.

[25] Yang, Y. C., Xing, H. G., Yang, X. G. (2018): Experimental study on the dynamic response and stability of bedding rock slopes with weak interlayers under heavy rainfall. - Environmental Earth Sciences 77(12): 433.

[26] Zhang, G. A., Wang, R., Qian, J. (2012): Effect study of cracks on behavior of soil slope under rainfall conditions. - Soils \& Foundations 52(4): 634-643.

[27] Zhang, J., Li, J., Lin, H. (2016): Models and influencing factors of the delay phenomenon for rainfall on slope stability. - European Journal of Environmental \& Civil Engineering 22(1): 1-15. 